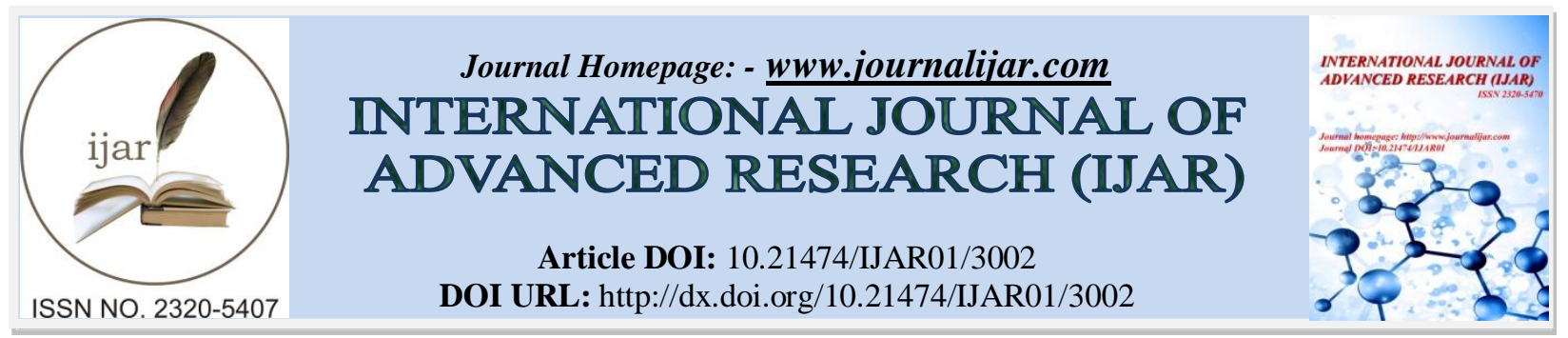

RESEARCH ARTICLE

\title{
SUBJECTIVE RESPONSE TO RESPIRATOR USE: COMPARISON N95, SURGICAL MASK AND FACE COVER.
}

\author{
Al-Zahrani $\mathbf{R}^{1}$, Bashihab $\mathbf{R}^{1}$, Al-Horaibi $\mathbf{H}^{1}$, Al-Nafesa $\mathrm{A}^{1}$, Emam $\mathbf{M}^{1}$, Al-Harthi $\mathrm{S}^{1}$, Al-Hajaj $\mathrm{B}^{1}$ and \\ Harber $\mathbf{P}^{2}$.
}

1. Al-Imam Muhammad Ibn Saud Islamic University, college of medicine, Riyadh-Kingdom of Saudi Arabia.

2. Professor of Public Health, Mel and Enid Zuckerman College of Public Health, University of Arizona

\section{Manuscript Info}

-......................

Manuscript History

Received: 28 November 2016

Final Accepted: 27 December 2016

Published: January 2017

\section{Abstract}

Cancer is a genome disease, initiated by mutations in genes that usually control cell growth and division. Matrix metalloproteinases (MMPs) have important roles in both of tumor invasion and spread.The present study was conducted to evaluate the effect of ionizing radiation (in the level of treatment doses of $\gamma$-rays). The action of collagenase gene was examined in vivo by using a model of solid tumor carcinoma (EAC). Eighty male mice were used for this experiment; it is divided into 8 groups, 10 mice / each; which were Normal and beside three groups of normal and like them of tumor transplanted mice each of them exposed to the following accumulated doses $(6,9$ and $12 \mathrm{~Gy})$. Whole body mice were exposed to gamma radiation from Cobalt-60 $\left({ }^{60} \mathrm{Co}\right)$ twice a week with different doses after 12 days of injected EAC in the right thigh region. The different doses of ionizing radiation exposure resulting in different changes (Mutations) on the sequence of collagenase gene in normal and malignant implanted groups and the level of these mutations were height in the malignant groups.

Copy Right, IJAR, 2016,. All rights reserved.

\section{Introduction:-}

Health care workers (HCW) are at risk of serious infectious diseases. Respiratory protective devices can reduce the risk. This project investigates how they tolerate them to determine if that affects proper use.

\section{Objectives:-}

To estimate the subjective effects upon users of respirators during activities comparable to healthcare work and to assess the effects of combining face covering and respirators among female health workers.

\section{Materials \& Methods:-}

This study is controlled experimental design with two factors: respirator type and activity type.

Measures of effects were based upon a rating instrument (questionnaire) designed by the Saudi Arabia Medical Students (SAMS) team. Ratings were based on ordinal 6 point scale. The following factors were measured: breathing difficulty, clarity of speech, heat and sweating, level of concentration, vision and comfortability.

Corresponding Author:- Al-Zahrani R.

Address:- Al-Imam Muhammad Ibn Saud Islamic University, college of medicine, Riyadh-Kingdom of Saudi Arabia. 
Tasks were designed to be comparable to common health care work. These included: walking outdoor, climbing stairs carrying an object, reading out loud (comparable to patient interviewing) and level of concentration (comparable to attending meetings).

The tasks were designed to range from mild activities such as level of concentration (attending a meeting) and reading to strenuous ones such as walking and climbing stairs (carrying an object).

The activities have been pilot tested before the conduction. Factors such as (walking distance, pace, duration, temperature, voice level and object's weight) have been standardized.

Mask conditions were: N95 Respirator (3M Model 1860), Basic surgical mask (Walgreens Model Model \# 023185056204), Face cover + N95 combination and No mask.

\section{Sampling Technique:-}

The order of tasks and mask type was assigned randomly among participants. Sixteen tasks sets of measures have been completed by each participant (4 mask conditions $\mathrm{x} 4$ tasks). The whole process of questionnaires administration and collection took about one week.

Participants for the phase ` 1 pilot trial: Seven female medical students had volunteered to participate, their age group was between (23-26 year-old), and they were all healthy.

Data collection methods, instruments used, measurements: Types of masks have been used are; respirators (N95) and basic surgical mask along with the well recognized face cover that is commonly used (Niqab).

\section{Results:-}

There were statistically significant effects of both respirator type and activity level (Mixed linear model, SAS Proc Mixed). Wearing a respirator (N95) combined with face cover by (Niqab) shows the highest score in the interference with breathing and the level of comfortability in an average of 2.01 and 2.45 , respectively. These differences were seen at all levels of exertion, not just the heaviest.

\section{Conclusions:-}

Better controlled studies are required to delineate whether such findings could be extended to those who are of different age groups, different sex such as bearded males and individuals with acute or chronic diseases in the Kingdom of Saudi Arabia.

\section{Acknowledgements:-}

We, the researchers, would like to extend our gratitude to all those people who helped and supported us in completing this project. Dr. Harber, Philip I. for supervising this project and Jing Su for helping us in data analysis. The Dean of College of Medicine Dr. Khalid Alqumaizi, Dr. Sami Aldaham and Dr. Aref Alrwaili for supporting us throughout the GHI program. We express our sincere gratitude to the Dean of Mel and Enid Zuckerman College of Public Health Dr. Iman Hakim, Cecilia Rosales and Jennifer L.Winkler for organizing the GHI program.

\section{References:-}

1. Harber, P., Bansal, S., Santiago, S., Liu, D., Yun, D., Ng, D., ... \& Wu, S. (2009). Multidomain subjective response to respirator use during simulated work. Journal of Occupational and Environmental Medicine, 51(1), 38-45.

2. For more information visit Wellington-Dufferin-Guelph Public Health, http://www.wdgpublichealth.ca /sites/default/files/wdgphfiles/Fact\%20Sheet\%20-

3. \%20Guide\%20to\%20Using\%20N95\%20Masks.pdf - Retrieved November, 2012.

4. Johnson, D. F., Druce, J. D., Birch, C., \& Grayson, M. L. (2009). A quantitative assessment of the efficacy of surgical and N95 masks to filter influenza virus in patients with acute influenza infection. Clinical Infectious Diseases, 49(2), 275-277.

5. For more information visit 3M Occupational Health and Environmental Safety Division,http://multimedia.3m.com/mws/mediawebserver?LLLLLLuS1X\&Leo4Lyo4LLlvv3wH kkkkJ- - Retrieved October, 2009.

6. Occupational Safety and Health Administration. (2007). Pandemic influenza preparedness and response guidance for healthcare workers and healthcare employers. Retrieved March, 14, 2008. 